\title{
Brown adipose tissue and the regulation of nonshivering thermogenesis.
}

Citation for published version (APA):

van Marken Lichtenbelt, W. D. (2012). Brown adipose tissue and the regulation of nonshivering thermogenesis. Current Opinion in Clinical Nutrition and Metabolic Care, 15(6), 547-552.

https://doi.org/10.1097/MCO.0b013e3283599184

Document status and date:

Published: 01/11/2012

DOI:

10.1097/MCO.0b013e3283599184

Document Version:

Publisher's PDF, also known as Version of record

Document license:

Taverne

Please check the document version of this publication:

- A submitted manuscript is the version of the article upon submission and before peer-review. There can be important differences between the submitted version and the official published version of record.

People interested in the research are advised to contact the author for the final version of the publication, or visit the DOI to the publisher's website.

- The final author version and the galley proof are versions of the publication after peer review.

- The final published version features the final layout of the paper including the volume, issue and page numbers.

Link to publication

\footnotetext{
General rights rights.

- You may freely distribute the URL identifying the publication in the public portal. please follow below link for the End User Agreement:

www.umlib.nl/taverne-license

Take down policy

If you believe that this document breaches copyright please contact us at:

repository@maastrichtuniversity.nl

providing details and we will investigate your claim.
}

Copyright and moral rights for the publications made accessible in the public portal are retained by the authors and/or other copyright owners and it is a condition of accessing publications that users recognise and abide by the legal requirements associated with these

- Users may download and print one copy of any publication from the public portal for the purpose of private study or research.

- You may not further distribute the material or use it for any profit-making activity or commercial gain

If the publication is distributed under the terms of Article $25 \mathrm{fa}$ of the Dutch Copyright Act, indicated by the "Taverne" license above, 


\title{
Brown adipose tissue and the regulation of nonshivering thermogenesis
}

\author{
Wouter van Marken Lichtenbelt
}

\begin{abstract}
Purpose of review
The recent rediscovery of functional cold activated brown adipose tissue (BAT) in adult humans fuelled an uprise in studies on this tissue. This review focuses on the contribution of human BAT to nonshivering thermogenesis and on factors other than cold that activate BAT.
\end{abstract}

\begin{abstract}
Recent findings
Earlier studies revealed BAT activity using a glucose tracer for positron emission tomography/computed tomography (PET/CT) scanning. Several recent studies, using a mix of tracers and PET/CT dynamic scanning showed that human brown fat is metabolically active and related to the perfusion of the tissue. The actual contribution of BAT to nonshivering thermogenesis still needs to be explored.

The last few years, several new factors that activate human BAT have been described. These studies also highlight the plasticity of brown and white adipose tissue. Some of these factors may have pharmacological significance.
\end{abstract}

\begin{abstract}
Summary
New PET/CT studies provide information on oxidative human BAT metabolism in vivo. This new information in combination with the study on factors activating BAT are promising with respect to management of obesity and related disorders.

Keywords

adaptive thermogenesis, facultative thermogenesis, oxidative metabolism, PET/CT scan, thermoneutral zone
\end{abstract}

\section{INTRODUCTION}

With respect to heat production in the cold the most well known and very effective response to cold is shivering. This, however, is a response to extreme cold, uncomfortable and cannot be attained for a prolonged time. Interestingly, as in many other mammals, adult humans can use mild cold-induced thermogenesis without shivering, so-called nonshivering thermogenesis (NST) $[1,2]$. NST in adults is highly variable [mean $7-30 \%$ of basal metabolic rate (BMR)] and blunted in obese and aged individuals [3-5]. In newborns, brown adipose tissue (BAT) is responsible for NST. In humans, it was for long believed that adults do not have significant amounts of BAT. Recently, it was shown that BAT is present and active in adult humans [6-8] and is negatively related to BMI or body fat percentage [7], and age [9]. BAT in adult humans is most commonly present in the supraclavicular and neck region, but also paravertebral, mediastinal, para-aortic and suprarenal localizations. In the mean time, several studies showed significant relations between skeletal muscle mitochondrial function and NST $[10,11]$.
Therefore, it is possible that both tissues may be involved. In this review, after an introduction on NST, the most recent studies on the contribution of BAT on whole body energy expenditure in adult humans will be discussed. Secondly, the studies that appeared in the last 2 years on activation of human BAT will be reviewed.

\section{NONSHIVERING THERMOGENESIS AND THE THERMAL NEUTRAL ZONE}

The thermoneutral zone (TNZ) is defined as the range of ambient temperatures at which

Department of Human Biology, NUTRIM School for Nutrition, Toxicology and Metabolism of Maastricht University Medical Center, Maastricht, The Netherlands

Correspondence to Wouter van Marken Lichtenbelt, Department of Human Biology, NUTRIM School for Nutrition, Toxicology and Metabolism of Maastricht University Medical Center, Maastricht, The Netherlands. Tel: +31 43 3881629; e-mail: markenlichtenbelt@maastricht university.nl

Curr Opin Clin Nutr Metab Care 2012, 15:547-552

DOI:10.1097/MCO.0b013e3283599184 


\section{KEY POINTS}

- Studies on human BAT using PET/CT scanning with several new tracers have shown that human brown fat is metabolically active and is related to nonshivering thermogenesis.

- Currently, there is enough evidence that human BAT can be recruited and/or activated upon weight loss and in the winter season.

- Several recently studied factors, such as Irisin and cardiac natriuretic peptides, have shown to stimulate browning of WAT.

- Mild cold is a noninvasive natural stimulator of BAT: a more varied indoor climate than prescribed by the current standards may improve health of humans and reduce energy consumption by the built environment.

- At least some previously identified adult human BAT depots are composed of brite/beige adipocytes.

temperature regulation is achieved only by control of sensible dry heat loss, that is, without regulatory changes in metabolic heat production (facultative thermogenesis) or evaporative heat loss (sweating) $\left[12,13^{-}\right]$. This means that thermoregulation in the TNZ only occurs through changes in heat loss by the skin (insulation), which is regulated by skin vasomotor control.

The TNZ will be different when insulation (such as clothing or subcutaneous fat), posture or basal energy metabolism vary. The TNZ is affected by physical fitness, age, body composition, but also to the amount of acclimatization to cold [13"]. Below the TNZ energy expenditure increases by NST and/or shivering thermogenesis.

Little information is available about mild cold acclimatization in humans on skin vasoconstriction (insulative response). More is known about cold acclimatization and the metabolic response, socalled adaptive thermogenesis. The classical study on the recruitment of cold-induced NST in humans is from Davis, 1961 [1]. Other studies indicate a concomitant elevation in sympathetic nervous system (SNS) activity with chronic exposure to cold. It is likely that both metabolic and insulative adaptation may occur [2].

Adaptive thermogenesis was studied with mild cold exposure in summer and winter seasons in the Netherlands, which is characterized by mild seasonal variations in temperatures [14]. The average metabolic (facultative, nonshivering) response during cold exposure was highly variable, but on average significantly higher in winter $(11.5 \%)$ compared with summer (7.0\%). The metabolic response in winter was significantly related to the response in summer, indicating that the relative magnitude of the cold response is an individual trait.

In conclusion, NST is very variable depending on the individual, the relative contribution of the insulative response and on the amount of cold acclimatization (adaptation), which may already occur in temperate climates. The most likely candidate tissues responsible for NST are BAT and skeletal muscle. Here, we will focus on the new insights in BAT biology.

\section{BROWN ADIPOSE TISSUE \\ THERMOGENESIS, PLASTICITY AND BRITE/BEIGE ADIPOCYTES}

In mammals adipose tissue is present in two different forms: white adipose tissue (WAT) and BAT. Although fat cells' prominent function is energy storage. On the contrary, the function of BAT is to transfer energy from food and energy stores into heat. Brown adipocytes are characterized by a light pink to dark red tone, due to the high vascularization and the cytoplasm, which consists of small fatfilled vacuoles and a large amount of mitochondria. The tissue is densely innervated by the sympathetic nervous system [15]. The high vascularization is necessary for oxygen supply and heat transport, the mitochondria for the heat production, the stored fat for fast energy supply when heat production is needed, and the SNS innervation for fast activation of the tissue. The heat production occurs by mitochondrial uncoupling. This uncoupling process is executed by uncoupling protein-1 (UCP1), a unique inner-membrane mitochondrial protein for BAT. UCP1 causes a reflux of protons into the mitochondrial matrix, bypassing the ATP synthase. Mitochondrial uncoupling leads to proton leakage, which induces heat dissipation by the uncoupling itself and the other parts of the phosphorylation process [16]. Though described in detail, in BAT, a regulated increase in mitochondrial uncoupling may also occur in other tissues, such as skeletal muscle. Apart from UCP1, there are several other proteins of the mitochondrial carrier protein family described. However, UCP1 is the only protein from this family that mediates NST in BAT, at least in rodents [17].

Counterintuitively, animal studies have suggested that brown adipocytes and skeletal muscle fibers (and not the white adipocytes) share a common developmental ancestry [18]. On the contrary, also WAT contain cells that can express high levels of UCP1 and, depending on (cold) stimulation, take on a brown cell-like appearance. Thus, classical brown fat in rodents is derived from a 
myf-5, muscle-like cellular lineage [19], whereas the 'brown-like' cells (called brite or beige) within white adipose depots are not [20]. Interestingly, several studies indicate that these two types of thermogenic cells are regulated differently. A very recent study provides evidence that BAT depots in adult humans in fact are composed of brite/beige adipocytes [21"'].

Some studies indicate the plasticity of BAT in adult humans. Retrospective studies show higher incidences of BAT in patients in winter season, but these kind of studies are hard to interpret. One study shows that in winter cold-induced BAT activity was significantly higher than in summer [6]. Recently, a weight-loss study in morbid obese patients showed that 1 year after bariatric surgery, BAT was increased in four out of 10 participants, showing that indeed recruitment can take place [22"]. Moreover, after weight loss, BAT-positive participants had significantly higher NST compared with BAT-negative participants.

\section{BROWN ADIPOSE TISSUE CONTRIBUTION TO NONSHIVERING THERIOCENESIS}

In the last few years, several studies appeared that investigated the contribution of BAT to NST. But how can we quantify the contribution of BAT to NST?

First of all we can use animal data from rodents. This approach is not very accurate and has led to too high estimates (20\% of daily energy expenditure) [23]. If allometric considerations are taken into account, the contribution of BAT is lower, $3-5 \%$ of BMR [24]. The latter seems to be more realistic, but actual measurements on BAT metabolic rate in vivo are badly needed.

Techniques used to study BAT activity in vivo consist of PET/CT scanning, though other techniques are being explored. To date, several different PET tracers have been used in dedicated BAT studies. The most widely used tracer is ${ }^{18} \mathrm{~F}$-fluorodeoxy glucose (FDG), a glucose label. The radioactive label is metabolically trapped in the cells and can later on be visualized by scanning. ${ }^{18}$ F-FDG can by means of dynamic PET/CT procedures quantify glucose uptake rate. Because, fatty acids from internal stores as well as from circulating fatty acids are most likely the main energy source, the fatty acids share needs to be estimated in order to calculate the contribution of BAT to whole body energy expenditure from ${ }^{18} \mathrm{~F}-\mathrm{FDG}$ data. By assuming that fats supplied $90 \%$ and glucose $10 \%$, and an estimated amount of BAT of $63 \mathrm{~g}$. Virtanen et al. [8] came to a contribution of BAT of $4.5 \%$ of BMR.

Recently, other tracers have been used in human BAT research: $\mathrm{H}_{2}{ }^{15} \mathrm{O}$ (blood perfusion),
${ }^{18}$ F-thiaheptadecanoic (THA) acid (fatty acid tracer), ${ }^{11} \mathrm{C}$-acetate (oxidative metabolism), ${ }^{15} \mathrm{O}_{2}$ (oxygen extraction), and $\mathrm{C}^{15} \mathrm{O}$ (blood volume). Orava et al. (2011) [25"'] compared cold and insulin activation of BAT using a combination of ${ }^{18}$ F-FDG and ${ }^{15} \mathrm{O}-\mathrm{H}_{2} \mathrm{O}$. They found that glucose uptake rate in cold activated BAT was 12-fold higher than in thermal neutral conditions. Glucose uptake was significantly related to perfusion, but not with NST. Whole body energy expenditure was related to BAT perfusion, however NST was not. Though, this is a very interesting study, it was not possible to derive the contribution of BAT thermogenesis to whole body NST.

Recently, Ouellet et al. (2012) [26"'] used PET with a mix of different tracers. With these tracers, they were able to quantify BAT oxidative metabolism (by ${ }^{11} \mathrm{C}$-acetate) and uptake of glucose (by ${ }^{18}$ F-FDG) and nonesterified fatty acid (NEFA; by ${ }^{18} \mathrm{~F}$-THA). They confirmed glucose uptake as in other studies. NEFA uptake was also significantly increased in the cold compared with other tissues, but relatively low. Probably, other sources of fatty acids, such as intracellular brown adipocyte triglycerides and circulating lipoproteins, may have had a large contribution to BAT metabolic activity. Interestingly, this study showed, based on ${ }^{11} \mathrm{C}$-acetate, a significant cold-induced activation of BAT oxidative metabolism. However, the actual contribution of BAT to NST cannot be deduced, because during the measurements both shivering and NST took place and no relation was found between the cold-induced thermogenesis and BAT oxidative metabolism.

Finally, Muzik et al. (2012) [27] studied oxidative metabolism in BAT using triple oxygen $\left({ }^{15} \mathrm{H}_{2}{ }^{15} \mathrm{O}\right.$, $\mathrm{C}^{15} \mathrm{O}$ and ${ }^{15} \mathrm{O}_{2}$ ) and FDG PET scans. Surprisingly their calculations revealed a mean BAT thermogenesis of $85 \mathrm{~kJ}$ per day only, which on average amounts to $6 \%$ of NST (1.4 kcal per day; less than 1\% of BMR) only. However, the low metabolic rate of oxygen may have been caused by the short $(20 \mathrm{~min})$ time of cooling before the ${ }^{15} \mathrm{O}_{2}$ tracer test (possibly no or little BAT activation), although $115 \mathrm{~min}$ was used to cool before the ${ }^{18}$ F-FDG test to show BAT activity. Nevertheless, the use of the combination of PETtracers is promising and future studies using more standardized cooling protocols will hopefully show what the actual contribution of BAT on our energy expenditure is.

\section{ACTIVATION OF THERMOGENESIS AND BROWN ADIPOSE TISSUE}

The SNS innervates thermogenic targets such as BAT and skeletal muscle [28]. The sympathetic control 
of facultative thermogenesis is mediated by three $\beta$-adrenoceptors [ $\beta$-adrenoceptors (ARs)], and not by $\alpha$-adrenoceptors. Noradrenaline signals via protein kinase A (PKA; cAMP-dependent protein kinase) to increase thermogenesis. In humans, Zingaretti et al. [15] showed that human brown adipocytes are innervated by the SNS, and Virtanen et al. [8] demonstrated the presence of the $\beta_{3}$-adrenergic receptor $\left(\beta_{3}-\mathrm{AR}\right) \mathrm{mRNA}$ in these cells. In nuclear medicine, blocking the $\beta_{1}$-AR and $\beta_{2}$-AR through administration of propranolol is used to decrease ${ }^{18} \mathrm{~F}-\mathrm{FDG}$ uptake in BAT in patients at room temperature [29].

NST is stimulated by the SNS, but also requires thyroid hormone [30]. Thyroid hormone is essential to maximize the responsiveness to catecholamines acting at the adrenergic receptor level as well as at several postreceptor steps in the catecholamine signalling pathways, particularly those initiated in the $\beta$-ARs [30]. Thus thyroid hormone and SNS work in concert to increase thermogenesis by means of mitochondrial uncoupling in brown adipocytes. Cold-induced adrenergic-receptor stimulation has both acute (activation of UCP1, stimulation of lipolysis) and chronic (UCP1 gene transcription, mitochondrial biogenesis, hyperplasia of BAT, recruitment of brown adipocytes in WAT) effects on BAT [28].

\section{RECENTLY STUDIED ACTIVATORS OF HUMAN BROWN ADIPOSE TISSUE}

During the last years there are several adrenergic and nonadrenergic activators of thermogenesis and BAT studied, but most of them in animals. They may have interesting consequences for human BAT activation, such as an unexpected result on alternatively activated macrophages on thermogenesis was published last year [31"]. Below follow only those activators that have been studied in humans (see also Fig. 1).

\section{Adrenergic stimulation}

Vosselman et al. [32"] recently measured BAT activity after systemic infusion of the nonselective $\beta$-agonist isoprenaline (ISO) and compared this with cold activated BAT activity. Though isoprenaline increased energy expenditure to similar levels as cold exposure, BAT was not activated during $\beta$-adrenergic stimulation. The result can have been caused by ISO induced high levels of free fatty acids that may have competed with glucose (FDG) uptake in BAT. Therefore, acipimox was used in part of the subjects to lower plasma FFA. However, this did not increase ISO-induced FDG uptake in BAT. A plausible explanation is that the systemic concentration of ISO reached in the plasma is not sufficient enough to trigger the $\beta$-ARs on the brown adipocytes. However, EE did increase, indicating that other tissues are responsible for the increased $\beta$-adrenergic thermogenesis. Interestingly, Cypess et al. 2012 [33"] independently obtained comparable results with the sympathomimetic drug ephedrine [33"]. Both mild cold and ephidrine stimulated energy expenditure, but contrary to cold ephedrine also increased heart rate, blood pressure, and several circulating metabolites. Nevertheless, cold increased BAT activity, whereas ephedrine did not.

\section{Cardiac natriuretic peptides}

Recently, Bordicchia et al. (2012) [34"'] published a study on human and mouse adipocytes that indicates that cardiac natriuretic peptides are able to activate the browning of the WAT. It is for long known that activation of $\beta$-ARs can induce browning of adipocytes within white fat depots. Natriuretic peptides, however, are hormones that are produced by the heart and act on the renal system. They exist in atrial (ANP) and ventricular (BNP) forms. NPs and $\beta$-AR agonists are comparable with respect to stimulating lipolysis. This study now shows that NPs use a similar pathway in the adipocyte as catecholamines to activate BAT, but use a different receptor and the signal cascade is via cGMP-dependent protein kinase (PKG) instead of PKA for the catecholamines. Their findings thus emphasize a role of the heart as a regulator of adipose tissue biology, with NPs controlling lipid metabolism and energy balance.

\section{Irisin}

Very recently a new myokine was found that induces browning of WAT [35"']. Bostrom et al. [35"'] showed that mice muscle cells, upon increased levels of PPAR $\gamma$ coactivator- $1 \alpha$ induce the expression of a protein FNDC5. After cleavage, FNDC5 is secreted into the blood stream. This form of FNDC5 is called Irisin. Irisin can bind to the surface to white adipocytes and induce the expression of UCP1, and a program of browning of WAT. Irisin is induced with exercise in both mice and humans. Increased levels of Irisin increase EE in mice.

The study is very interesting, because Irisin is present in humans and increases in response to exercise. In addition, exogenously administration of Irisin induces the browning of subcutaneous fat and thermogenesis, and it likely can be prepared as an injectable polypeptide.

\section{Capsinoids}

Food can increase whole body thermogenesis and activate BAT. Diet-induced thermogenesis consists of an obligatory part (handling of food) and a 


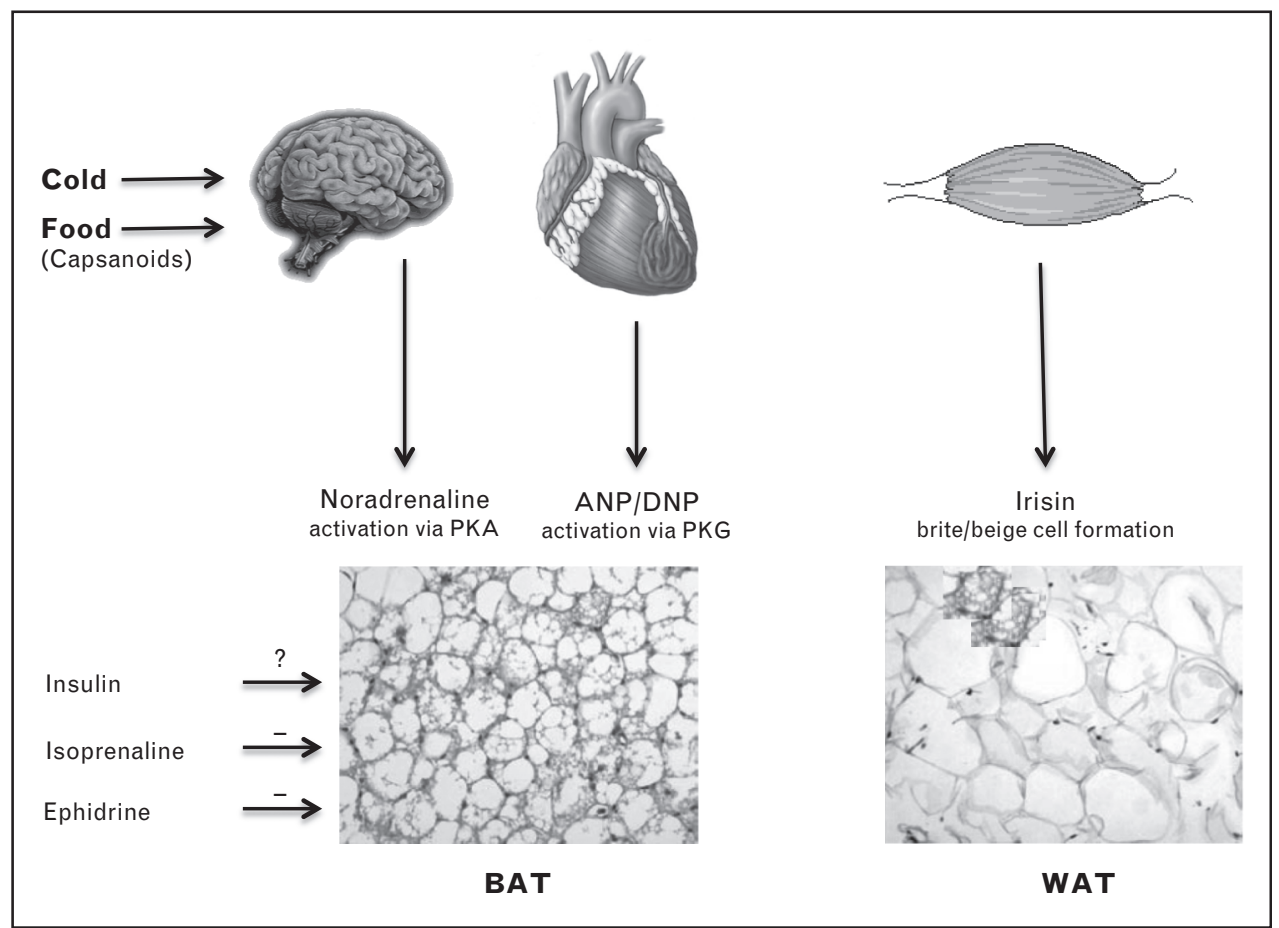

FIGURE 1. Recently studied activators of human brown adipose tissue (BAT). Apart from well known activation of BAT via the sympathetic nervous system by cold and diet, other nonadrenergic factors may affect BAT thermogenesis or brown (-like) adipocyte recruitment. Indicated are capsanoids, which are suggested to increase BAT activity via the sympathetic nervous system (SNS), isoprenaline and ephedrine, which both affect thermogenesis but not BAT activation at the concentrations studied. Insulin increased glucose uptake in BAT, but probably not BAT thermogenesis. Cardiac natriuretic peptides (ANP and BNP) activate BAT via the PKG signaling pathway. Irisin, a myokine, induces browning of white adipose tissue (WAT).

facultative (regulated) part. Nutritional studies on BAT activation have not yet been published, except for a study with capsinoids [36"]. Capsinoids are a capsaisin analog (known from red peppers). They are less pungent, yet as potent in increasing EE and fat oxidation through the activation of the adrenosympathetic nervous system [37]. The study was carried out with oral ingestion of capsanoid or placebo in a group with cold activated BAT and a group without cold-activated BAT [36"]. The cold activated BAT PET/CT tests were carried out separately from the capsanoid test on whole body energy expenditure. The results revealed that EE was significantly higher in response to capsinoids in the BAT-positive group than in the BAT-negative group. This indirectly suggests that BAT is involved in capsinoid induced energy expenditure. It would be interesting to perform as a follow-up a direct measurement studying FDG uptake in BAT by PET/CT with and without capsinoid ingestion.

\section{Insulin}

It is well known that skeletal muscle is sensitive to insulin, but from human BAT, no information was available. Using ${ }^{15} \mathrm{O}-\mathrm{H}_{2} \mathrm{O}$ and ${ }^{18} \mathrm{~F}$-FDG PET/CT insulin sensitivity of BAT was studied in adult humans
[25"']. Their results show that glucose uptake in the cold was increased 12-fold in BAT, and five-fold when insulin stimulated under thermoneutral conditions. Thus, BAT appears to be differently activated by insulin and cold. Insulin induced FDG uptake in BAT was higher than in WAT, but comparable to skeletal muscle. The insulin-mediated activation of BAT metabolism seemed to be independent on the increased tissue perfusion. The reason can be that no extra oxygen may have been needed (as is the case in cold activation), probably because insulin did not activate BAT thermogenesis.

\section{CONCLUSION}

Recent studies using PET/CT scanning techniques show that human brown fat is metabolically active and is related to NST. The use of a combination of different PET-tracers is promising and future studies likely will unravel the actual contribution of BAT on human energy expenditure.

There are several indications that human BAT can be recruited.

In the last few years, several factors have been studied that affect activity and recruitment of human BAT. Factors, such as irisin and cardiac natriuretic peptides could be therapeutic for human 
metabolic disease. The future will show whether such factors or related pharmaceuticals will have relevance for treatment. Thus far, we only know that mild cold activation effectively activates BAT in humans without noticeable side-effects. Health may benefit from thermal stimulation by an indoor climate outside that established by the current standards. Variable indoor temperatures (seasonal and daily) may cut both ways: allowing more variable temperatures outside the TNZ can improve health by BAT activation and increasing thermogenesis in humans and in the mean time reduce energy consumption by the built environment.

\section{Acknowledgements}

The authors thank the Thermu group (www.thermu.eu) for fruitful discussions and Maarten Vosselman for critically reading the article. This work was supported by the Netherlands Science Foundation ZonMw (TOP 91209037 to W.D.v.M.L.) and by the EU FP7 project DIABAT (HEALTH-F2-2011-278373).

\section{Conflicts of interest}

There are no conflicts of interest.

\section{REFERENCES AND RECOMIMENDED}

\section{READING}

Papers of particular interest, published within the annual period of review, have been highlighted as:

- of special interest

m. of outstanding interest

Additional references related to this topic can also be found in the Current

World Literature section in this issue (p. 659)

1. Davis TRA. Chamber cold acclimatization in man. J Appl Physiol 1961; 16:1011-1015.

2. van Marken Lichtenbelt WD, Schrauwen $P$, Kerckhove Svd, WesterterpPlantenga MS. Individual variation in body temperature and energy expenditure in response to mild cold. Am J Physiol 2002; 282:E1077-E1083.

3. Warwick PM, Busby R. Influence of mild cold on $24 \mathrm{~h}$ energy expenditure in 'normally' clothed adults. Br J Nutr 1990; 63:481-488.

4. Claessens-van Ooijen AM, Westerterp KR, Wouters L, et al. Heat production and body temperature during cooling and rewarming in overweight and lean men. Obesity (Silver Spring) 2006; 14:1914-1920.

5. Kingma BRM, Frijns AJH, Saris WHM, et al. Increased systolic blood pressure after mild cold and rewarming: relation to cold-induced thermogenesis and age. Acta Physiologica 2011; 203:419-427.

6. Saito M, Okamatsu-Ogura $\mathrm{Y}$, Matsushita $\mathrm{M}$, et al. High incidence of metabolically active brown adipose tissue in healthy adult humans: effects of cold exposure and adiposity. Diabetes 2009; 58:1526-1531.

7. van Marken Lichtenbelt WD, Vanhommerig JW, Smulders NM, et al. Coldactivated brown adipose tissue in healthy adult men. New Engl J Med 2009; 360:1500-1508.

8. Virtanen KA, Lidell ME, Orava J, et al. Functional brown adipose tissue in healthy adults. N Engl J Med 2009; 360:1518-1525.

9. Yoneshiro T, Aita S, Matsushita M, et al. Age-related decrease in coldactivated brown adipose tissue and accumulation of body fat in healthy humans. Obesity $2011 ; 19: 1755-1760$.

10. Wijers SLJ, Schrauwen $P$, Saris WHM, van Marken Lichtenbelt WD. Human skeletal muscle mitochondrial uncoupling is associated with cold induced adaptive thermogenesis. PlosOne 2008; 3:e1777.

11. Wijers SL, Schrauwen $P$, van Baak MA, et al. Beta-adrenergic receptor blockade does not inhibit cold induced thermogenesis in humans: possible involvement of brown adipose tissue. J Clin Endocrinol Metab 2011;96:E598E605.

12. IUPS-Thermal-Commission. Glossary of terms for thermal physiology. 3rd ed. Thermal Biol 2003; 28:75-106.

13. Kingma BRM, Frijns AJH, van Marken Lichtenbelt WD. The Thermoneutral

- Zone: implications for metabolic studies. Front Biosci 2012; 4:1975-1985.

This article describes the recent insights and implications of the thermal neutral zone on metabolic studies.
14. van Ooijen AMJ, van Marken Lichtenbelt WD, van Steenhoven AA, Westerterp K. Seasonal changes in metabolic and temperature responses to cold air in humans. Physiol \& Behav 2004; 82:545-553.

15. Zingaretti MC, Crosta $F$, Vitali $A$, et al. The presence of UCP1 demonstrates that metabolically active adipose tissue in the neck of adult humans truly represents brown adipose tissue. Faseb J 2009; 23:3113-3120.

16. Cannon B, Nedergaard J. Brown adipose tissue: function and physiological significance. Physiol Rev 2004; 84:277-359.

17. Nedergaard J, Golozoubova V, Matthias A, et al. UCP1: the only protein able to mediate adaptive nonshivering thermogenesis and metabolic inefficiency. Biochim Biophys Acta 2001; 1504:82-106.

18. Timmons JA, Wennmalm $K$, Larsson $O$, et al. Myogenic gene expression signature establishes that brown and white adipocytes originate from distinct cell lineages. Proc Natl Acad Sci U S A 2007; 104:4401-4406.

19. Seale $P$, Bjork $B$, Yang $W$, et al. PRDM16 controls a brown fat/skeletal muscle switch. Nature 2008; 454:961-967.

20. Petrovic N, Walden TB, Shabalina IG, et al. Chronic peroxisome proliferatoractivated receptor gamma (PPARgamma) activation of epididymally derived white adipocyte cultures reveals a population of thermogenically competent, UCP1-containing adipocytes molecularly distinct from classic brown adipocytes. J Biol Chem 2010; 285:7153-7164.

21. Wu J, Bostrom $P$, Sparks $L M$, et al. Beige adipocytes are a distinct type of I. thermogenic fat cell in mouse and human. Cell 2012; 150:366-376.

This study that combines data from mice, cell lines and human brown adipocytes makes it likely that the brown fat of adult humans is composed of brite/beige adipocytes.

22. Vijgen GH, Bouvy ND, Teule GJ, et al. Increase in brown adipose tissue

- activity after weight loss in morbidly obese subjects. J Clin Endocrinol Metab 2012; 97:E1229-E1233.

This is the first article that shows BAT recruitment in humans after weight loss.

23. Rothwell NJ, Stock MJ. A role for brown adipose tissue in diet-induced thermogenesis. Nature 1979; 281:31-35.

24. van Marken Lichtenbelt WD, Schrauwen P. Implications of nonshivering thermogenesis for energy balance regulation in humans. Am J Physiol Regul Integr Comp Physiol 2011; 301:R285-R296.

25. Orava J, Nuutila $P$, Lidell ME, et al. Different metabolic responses of human

- brown adipose tissue to activation by cold and insulin. Cell metabolism 2011; $14: 272-279$.

This is an elegant study using elaborate PET/CT dynamic scanning to show human BAT activity and perfusion in response to cold exposure and insulin.

26. Ouellet V, Labbe SM, Blondin DP, et al. Brown adipose tissue oxidative

- metabolism contributes to energy expenditure during acute cold exposure in humans. J Clin Investig 2012; 122:545-552.

This is an extended study using a large mix of PET/CT tracers to show for the first time that human BAT oxidative metabolism is increased upon cold exposure.

27. Muzik O, Mangner TJ, Granneman JG. Assessment of oxidative metabolism in brown fat using PET imaging. Front Endocrinol 2012; 3:15.

28. Lowell BB, Spiegelman BM. Towards a molecular understanding of adaptive thermogenesis. Nature 2000; 404:652-660.

29. Soderlund V, Larsson SA, Jacobsson H. Reduction of FDG uptake in brown adipose tissue in clinical patients by a single dose of propranolol. Eur J Nucl Med Mol Imaging 2007; 34:1018-1022.

30. Silva JE. Thermogenic mechanisms and their hormonal regulation. Physiol Rev 2006; 86:435-464.

31. Nguyen $K D$, Qiu $Y$, Cui $X$, et al. Alternatively activated macrophages produce

- catecholamines to sustain adaptive thermogenesis. Nature 2011;480:104108.

This is an interesting study in rodents that shows that macrophages can play an essential role in activation of BAT.

32. Vosselman MJ, van der Lans AAJJ, Brans B, et al. Systemic beta-adrenergic

- stimulation of thermogenesis is not accompanied by brown adipose tissue activity in humans. Diabetes 2012 [Epub ahead of print].

This study shows that a nonselective $\beta$-agonist isoprenaline increases energy expenditure but does not activate human BAT.

33. Cypess AM, Chen YC, Sze C, et al. Cold but not sympathomimetics activates - human brown adipose tissue in vivo. Proc Natl Acad Sci U S A 2012.

This study shows that a sympathomimetic drug ephedrine increases energy expenditure and heart rate, but does not activate human BAT.

34. Bordicchia M, Liu D, Amri EZ, et al. Cardiac natriuretic peptides act via p38

- MAPK to induce the brown fat thermogenic program in mouse and human adipocytes. J Clin Investig 2012; 122:1022-1036.

This article demonstrates nicely a novel mechanism for increasing BAT thermogensis independent of adrenergic receptors.

35. Bostrom P, Wu J, Jedrychowski MP, et al. A PGC1-alpha-dependent myokine

a. that drives brown-fat-like development of white fat and thermogenesis. Nature $2012 ; 481: 463-468$.

This interesting article on a new myokine called irisin demonstrates how exercising muscles can regulate browning of WAT.

36. Yoneshiro T, Aita S, Kawai Y, et al. Nonpungent capsaicin analogs (capsi-

- noids) increase energy expenditure through the activation of brown adipose tissue in humans. Am J Clin Nutr 2012; 95:845-850.

This is the first article on the activation of BAT by a food component.

37. Luo XJ, Peng J, Li YJ. Recent advances in the study on capsaicinoids and capsinoids. Eur J Pharmacol 2011; 650:1-7. 